\title{
SWEP'd up for the Summer: Survey of participants' experiences of a nursing student research internship
}

\author{
Julia Kruizinga ${ }^{*}$ Chloe Coulson, Stephanie Saunders, Nicole Ning \\ Queen's University, Canada
}

Received: April 27, 2020

Accepted: May 26, 2020

Online Published: June 14, 2020

DOI: $10.5430 /$ jnep.v10n9p65

URL: https://doi.org/10.5430/jnep.v10n9p65

\begin{abstract}
Background: Queen's University (Ontario, Canada) has been offering the Summer Work Experience Program (SWEP) -a subsidized work opportunity for university undergraduate students- since 1995. The Queen's University Nursing and Health Research Internship program, established in May 2017, involves nursing SWEP students. The program was designed to build research knowledge and experience for nursing students. The aim of this article is to describe the program components, and intern and faculty insights.

Methods: To obtain feedback from current and past interns and faculty, an electronic survey was distributed. Data were analyzed for common themes.

Results: Themes consolidated from interns $(n=4)$ included challenges as learning opportunities, new perspectives on research, and successes and opportunities. Themes that emerged from faculty $(n=7)$ were program challenges and successes, and needs and concerns of interns.

Conclusions: Overall, interns and faculty members perceived the program as a valuable learning experience. Suggestions for program development and potential changes are discussed from both an intern and faculty perspective. Further recommendations for program development are explored, with potential changes for future offerings.
\end{abstract}

Key Words: Undergraduate research, Nursing, Research development, Internship, Experiential learning

\section{INTRODUCTION}

According to the Canadian Nurses Association, research and scholarship are considered domains within nursing practice. ${ }^{[1]}$ Participation in research activities during undergraduate education is purportedly beneficial to students, as it leads to improvement in knowledge translation, critical thinking skills, and the development of more integrated scholarly identities. ${ }^{[2]}$ Engaging in research courses and activities is additionally important as it exposes students to opportunities that reinforce the scientific foundation of the nursing profession. ${ }^{[1]}$ This foundation leads to new knowledge generation for improved evidence-informed care and nursing practice. ${ }^{[3]}$
While research is not typically a responsibility associated with an entry-level nurse, ${ }^{[4]}$ a foundational understanding of nursing research is important to be able to critique and make decisions about the applicability of published nursing research for practice and to identify research questions. Undergraduate nursing students in Canada usually complete a research course, but rarely have the opportunity to apply the theoretical knowledge with a 'hands-on' approach in research and scholarship activities. ${ }^{[5]}$ Thus, nursing students lack exposure to actively participate in and contribute to research and apply research skills.

*Correspondence: Julia Kruizinga; Email: j.kruizinga @ queensu.ca; Address: Queen’s University, Canada. 


\subsection{Literature review}

In an ever-changing landscape of healthcare, evidence-based practice (EBP) is needed to inform nursing care. ${ }^{[6]}$ Establishing an understanding and appreciation of EBP at the undergraduate level prepares students to utilize the best available research in clinical decision-making. ${ }^{[7-9]}$ Therefore, participating in research activities helps to develop the knowledge, skills and competencies within nursing practice and potentially contributes to better patient outcomes. ${ }^{[10-12]}$

Numerous post-secondary nursing programs have implemented opportunities aimed at engaging students in research and improving their knowledge of the nurse's role in EBP. ${ }^{[2,12,13]}$ These programs varied in their approaches and outcomes, however, all programs exposed students to research and fostered an appreciation for this domain of nursing practice. ${ }^{[2,12,14-17]}$ Many of these programs hired and paid undergraduate nursing students to work with faculty members on research projects of their interest, ${ }^{[2,12,16]}$ where funding for student wages was secured from either the parent university or from government sources. ${ }^{[14,16]}$ Students worked during the academic year or summer break, and were paid either part-time or full-time. ${ }^{[13,14,16]}$ Tasks completed by students in three separate research programs consisted of examining the literature pertaining to specific projects as well as data retrieval or analysis, ${ }^{[2,13,16]}$ while one program specifically offered research projects within a hospital setting. ${ }^{[16]}$ The findings from the hospital-based research program concluded that students involved in clinical-based research studies better understood the barriers of integrating EBP into patient care. ${ }^{[16]}$

Findings, largely based upon qualitative data collection, revealed that immersing students in the research process helped them grow in knowledge and develop an appreciation for nursing research. ${ }^{[12,14-16]}$ Positive feedback was received from students across several studies, ${ }^{[2,7,12,15,16]}$ as students were generally satisfied with their experience working in research. $^{[2]}$ Collectively, these studies indicate that such programs are useful to positively change the perceptions of nursing students towards research and promote increased engagement in subsequent academic research. ${ }^{[12]}$

Although the studies outlined above included small sample sizes and lack of input from faculty on program strengths and areas for improvement, the findings are collectively useful to illuminate the advantages of such programs. ${ }^{[2,13,16]}$ For instance, authors from three separate programs noted that benefits from research internships included increased interest in further nursing education following undergraduate study ${ }^{[12,14]}$ and use of research in the clinical setting. ${ }^{[16]}$ With the encouragement of nurses and nursing students to pursue research or advanced practice roles, it is important that opportunities are provided as early and frequently as possible. Within a centralized university program (SWEP), the Queen's Nursing and Health Research Internship program provides the structure and support for both students and faculty to collaboratively engage in research. The Queen's Nursing and Health Research Internship is unique from other research internships or honors stream in nursing programs because it involves an inter-collaborative model that brings together a team of research interns and faculty members, where interns have the opportunity to work on several research projects at various stages of the research process. The purpose of this article was to describe the experiences of research interns and faculty members involved in an inter-collaborative and innovative Nursing and Health Research Internship program.

\subsection{Program overview}

The Summer Work Experience Program (SWEP) was established at Queen's University in 1995 to provide undergraduate students with an engaging summer work experience and an opportunity to build transferrable skills, which may be applied to future career opportunities. The program provides a centralized hub for faculty members and students to work together on a variety of projects, in addition to providing a wage subsidy to faculty. For the summer of 2019, approximately $70 \%$ of SWEP applications received from faculty members (167 of 283) were approved through a competitive process, of which $50 \%$ were research-based. Since the genesis of the Nursing and Health Research Internship, seven intern positions were approved for the School of Nursing Queen's Nursing and Health Research (QNHR) group.

\subsection{Queen's nursing and health research - program de- scription, objectives and goals}

The QNHR group is home to 17 faculty members of the School of Nursing at Queen's University. It is composed of a team of nurse researchers who collectively, and in collaboration with practice and academic partners, lead and facilitate comprehensive research programs. In May of 2017, the Queen's Nursing and Health Research Internship Program was established as a component of the QNHR, with the goal of promoting undergraduate nursing student engagement in research. The philosophy behind the research internship is to create an inter-collaborative model between faculty and undergraduate nursing students to provide research mentorship and skill development to the research interns while advancing faculty research. Faculty projects provide the opportunity to learn research activities, including but not limited to: ethics submission preparation and process, data collection and analysis, knowledge translation activities (i.e., video preparation related to breast cancer recovery, attendance at research sem- 
inars) and scholarly writing or reporting. Fourteen faculty members have been involved with the Queen's Nursing and Health Research Internship over the past three years, each bringing a major research project to the table.

The QNHR Research Internship offers paid employment for the months of May through August for a duration of 16 weeks, within which 35 hours of work per week is required. The interns are paid a universal wage consistent between all SWEP positions at Queen's University (e.g., \$16/hr). Nursing students from the four-year stream who had completed their second or third year were eligible to apply for an intern position. As part of the SWEP application process, interested undergraduate nursing students had the opportunity to review the faculty research projects and activities, which included targeted learning goals and outcomes. Successful applicants then collaborated with faculty to select activities that best matched their personal and professional interests. Interns had the opportunity to participate in a variety of tasks that contributed to the refinement of their research knowledge through participation in research and scholarly activities. All interns participated in joint learning activities, such as attendance at the Joanna Briggs Institute (JBI) systematic review course. Interns were further engaged with activities such as research and educational seminars, knowledge translation activities and research and professional development experiences.

One of the innovative facets of the research internship was bringing together a group of interns with multiple faculty mentors to work on a variety of research projects. Over the course of the summer, interns collectively attended bi-weekly meetings with the research coordinator and all involved faculty. While agendas varied, meetings were structured to appraise the group about intern and project progress, plan for supplemental learning and research opportunities, and resolve any operational issues. In addition, interns maintained regular communication with their faculty mentors to further discuss the details of individual projects. This collaborative model catalyzed learning, as it encouraged regular collaboration amongst faculty members and research interns, built peer support and decreased the risk of isolation.

\section{MethodS}

\subsection{Settings and sample}

This study was conducted in Kingston, Ontario at Queen's University School of Nursing. All faculty members and research interns who had been involved in any or all of the cohorts since the inception of the QNHR Research Intern- ship in May 2017 were invited to participate, which included seven research interns and fourteen faculty members.

\subsection{Data collection}

In gaining perspectives about the QNHR Research Internship, an anonymous electronic qualitative survey was designed and distributed by the authors (J.K., C.C., S.S.) for both research interns and faculty members who had ever participated in the program. ${ }^{[18]}$ The survey for participants differed as research interns answered five questions and for faculty members, four questions. The questions were developed to understand the experience of being involved in the QNHR Research Internship, with questions focused on illuminating the challenges, learning, development and opportunities of both research interns and faculty members. The surveys were sent by email to all previously involved research interns and faculty members in the three cohorts of the QNHR Research Internship, and consent was obtained by participants for the use of their feedback for program evaluation and/or inclusion in this article. Data was anonymously collected in August 2019 through Qualtrics, a secure online platform.

\subsection{Data analysis}

The feedback from the survey results of interns $(n=4)$ and faculty $(n=7)$ was analyzed and grouped into themes by the authors (J.K., C.C., S.S.) using a thematic analysis framework. ${ }^{[19]}$ The authors read the feedback and identified codes, subthemes and emerging themes independently using Microsoft Excel. The final themes were agreed upon through discussion and consensus (see Table 1). The themes that will be explored from a faculty perspective are perceived needs and concerns of interns and perceived successes and challenges, and from a research intern perspective are challenges as learning opportunities, new perspectives on nursing research and professional opportunities and successes.

\subsection{Ethical consideration}

Participants had the opportunity to complete the survey once consent was provided and they were made aware of the confidential nature in participating to minimize coercion or undue influence. The survey was designed through Qualtrics to not collect any identifying information in order to maintain anonymity and efforts were made to keep data confidential through password protected documents stored on Microsoft OneDrive. These documents were only accessible to those directly involved in data analysis. Ethics approval was obtained through the Queen's University Health Sciences Research Ethics Board (HSREB \# NURS-473-19). 
Table 1. Perspectives, themes and corresponding sub-themes from faculty and interns survey feedback

\begin{tabular}{|c|c|c|}
\hline Perspectives & Themes & Corresponding Sub-Themes \\
\hline \multirow{3}{*}{$\begin{array}{l}\text { Research } \\
\text { Interns }\end{array}$} & Challenges as learning opportunities & $\begin{array}{l}\text { Challenges for students, learning from challenges, applying skills through } \\
\text { challenges }\end{array}$ \\
\hline & New perspectives on nursing research & $\begin{array}{l}\text { Learning from challenges, defining research in nursing, gained appreciation } \\
\text { for research }\end{array}$ \\
\hline & Opportunities and successes of interns & $\begin{array}{l}\text { Opportunities from this internship, professional connections, taking what was } \\
\text { learned into nursing practice (skills), taking what was learned into nursing } \\
\text { practice (theoretical) }\end{array}$ \\
\hline \multirow{2}{*}{$\begin{array}{l}\text { Faculty } \\
\text { Members }\end{array}$} & $\begin{array}{l}\text { Needs and concerns of interns } \\
\text { perceived by faculty }\end{array}$ & $\begin{array}{l}\text { Needs for students to be successful in research, concerns for students in the } \\
\text { program }\end{array}$ \\
\hline & $\begin{array}{l}\text { Challenges and successes perceived } \\
\text { by faculty members }\end{array}$ & $\begin{array}{l}\text { Benefits to faculty members, benefits to faculty research, faculty still } \\
\text { growing, actions/activities that lead to success in the program, student growth }\end{array}$ \\
\hline Shared & Symbiotic relationship & $\begin{array}{l}\text { Benefits to faculty members, benefits to faculty research, opportunities from } \\
\text { this internship, professional connections }\end{array}$ \\
\hline
\end{tabular}

\section{SURVEY RESULTS}

The survey results were analyzed and organized by the authors (J.K., C.C., S.S.) into the following reported codes that were then grouped into themes and subthemes. Three major themes emerged from research interns, two major themes from faculty members and one joint theme from both research interns and faculty members. Theme descriptions include the authors interpretive analysis and are reported on themes iteratively agreed upon by the authors to describe the experience of research interns and faculty members within an innovative Nursing Health and Research Internship program. ${ }^{[19]}$

\subsection{Themes - Research interns}

\subsubsection{Challenges as learning opportunities}

Research interns experienced various challenges during this program. There were organizational challenges, such as overlapping projects and deadlines, keeping track of hours, and seeking supports. As one intern stated it was "sometimes challenging to anticipate what was next while establishing a flexible schedule for short- and long-term projects" (Research Intern 1). Identified challenges were related to the individual's lack of experience in certain areas, for example learning to write a manuscript, or time management. These challenges led to growth and learning as the intern's skills and abilities developed. Further, the diverse, unpredictable and non-linear nature of faculty research was a challenge. Research interns were exposed to situations where they perceived they lacked skill level or did not have sufficient direction to complete tasks. When research interns felt uncertain or felt that they lacked direction, they sought guidance from faculty supervisors. One intern wrote, "sometimes you just have to stop overthinking [...] and just do it" (Research Intern 1), and another intern emphasized the need to "advocate more clearly and frequently for learning needs" (Research Intern 3). Key supports identified by interns that led to their success were having regular meetings with supervisors, biweekly group meetings with faculty, other interns and the research coordinator, infrastructure with external support personnel (e.g., librarian, and information technology personnel) and research training courses (e.g., TCP2-Course on Research Ethics; Joanna Briggs Institute Comprehensive Systematic Review training).

\subsubsection{New perspectives on nursing research}

The interns recognized that the research internship was an opportunity to consolidate research knowledge. One intern explained, "I was so confused and intimidated by research" (Research Intern 1), but through being involved in the research internship, was able to consolidate research concepts through being immersed in the research process. Interns had the opportunity to be immersed in various aspects of the research process, which is a very different approach compared to traditional didactic learning. The interns from this program gained a much greater regard for research and its applicability in nursing. One intern's perspective changed as they learned "research is just as much about educating others as it is about educating oneself" (Research Intern 3). Working alongside faculty supervisors, the interns were able to gain insight to what faculty members do aside from their teaching and service responsibilities.

\subsubsection{Professional opportunities and successes}

The interns identified several significant opportunities for professional development unique to this program. Profes- 
sional development was a recurring opportunity, as interns were able to network with faculty, work towards publication of manuscripts in academic journals, develop academic and interpersonal skills, and be offered further employment to continue research throughout the academic year. One intern appreciated the "unique and active mentoring relationship between faculty and interns" (Research Intern 2), while another intern stated the mentoring relationship was critical to "forming their identity as a novice researcher" (Research Intern 3). During interns' involvement in the program, they had the opportunity to be included and be known by faculty and administrative staff and participate in events on and off campus. One intern stated they "felt they were a part of the school in a different way" (Research Intern 2).

\subsection{Themes - Faculty members}

\subsubsection{Faculty perception of interns' needs and concerns}

Faculty members' responses were aggregated into a theme that captured the needs and concerns for students in the research internship. One faculty member said, "I worry that some students are left not supported enough and therefore don't learn as much as possible" (Faculty Member 3). Faculty members reflected on the increased needs of research interns as "interns are only undergraduate students who have taken a research course that is simply an overview of research methods" and are "lacking the applied research skills" (Faculty Member 3). The lack of experience was an important concept for faculty members to recognize when engaging with the interns and to appreciate.

\subsubsection{Success and challenges perceived by faculty}

There were numerous successes about the research internship as perceived by faculty. Faculty identified that interns taught them about how to use technology to expedite the research process, motivated faculty to complete research projects, and with the help of the interns, faculty were able to complete their research projects more efficiently. One faculty member stated, "students keep aspects of the research on track and allow opportunities to explore pilot or feasibility work", and one benefit of the research internship is its "core educational and training opportunities" (Faculty Member 2). The program allowed faculty to work with students on a one-one basis, which laid a foundation for "student engagement in research" (Faculty Member 2).

By contrast, concerns raised by faculty members included expectations of knowledge possessed by interns, awareness of current level of interns' research experience, and adapting to the role as a supervisor. One faculty member commented there were "not challenges, but rather "realities" (Faculty Member 2) of working with interns who are eager to learn and contribute to the research process. However, one faculty

Published by Sciedu Press member wrote "challenges can be rectified with open communication about expectations between faculty and students early on in the research relationship" (Faculty Member 3).

\subsection{Shared Perspectives by Faculty and Interns 3.3.1 Symbiotic relationship}

The relationship between faculty and interns was described as symbiotic in nature and a "win-win" (Faculty Members 5 and 7). One faculty member said the program simultaneously advanced the intern experience and contributed to faculty output. This program served to build research capacity through reduced cost and provided enriching experiential work for interns. Due to the close working relations and bi-weekly meetings, faculty were able to "reflect on their mentoring skills" and interns were able to "reflect on their accomplished learning" (Faculty Member 3). As one faculty member wrote, "[the program] helped me better understand how to work with students/RAs at varying levels of research assistance" (Faculty Member 7). Faculty members were valued for their mentorship and engagement among research interns, and interns were regarded as a "high functioning member of a research team" (Faculty Member 3). Faculty members also agreed that interns "brought energy and good ideas" (Faculty Member 6). Within faculty members and interns' symbiotic relationship was the development of technological proficiency. While interns were not always familiar with new software, they learned quickly, and faculty jointly learnt from interns. Another mutual advantage identified was the increased pace of research, as one faculty member noted, "my projects kept moving forward faster than I imagined" (Faculty Member 3). Thus, interns had greater opportunity to work towards publication and acknowledgements for their research projects.

\section{Discussion}

Through the engagement of research interns and support and guidance of faculty members, the QNHR Research Internship program provided research mentorship and skill development to the research interns while advancing faculty research. Prior to the research internship, students may have had limited exposure to research experiences. However, in establishing an inter-collaborative model between faculty and undergraduate nursing students, research interns were provided with an experience to be a part of an innovative program that fosters relationships and mutual research engagement between faculty members and research interns.

For research interns, the successes of the program included professional growth and the ability to be a part of unique opportunities. Interns additionally emphasized the benefits of a mentoring relationship with faculty members and the 
development of novice research identities. While there were challenges of being a research intern, in many cases these challenges led to unexpected growth in time management, flexibility, advocacy and new research skills. Lastly, the research interns gained new perspectives of the applicability of nursing research and the nurse's role in research. These reflections gave interns a new outlook on the purpose of research in the nursing paradigm and increased their appreciation for the research process. Further research into the long-term effects of research programs and models, such as QNHR's model, is also necessary to identify the full impact of such programs. Faculty members likewise noted successes of the research internship, which included the expedition of the research process through new technology, an accelerated pace and broader scope of their intended research projects and feeling motivated by research interns' enthusiasm and energy. Future research would be beneficial to explore the effects of intern involvement on specific research outcomes, such as publications.

Interns developed valuable and transferable skills in the areas of interpersonal communication, comprehension and critical thinking, time management and prioritization, and advocacy. The aforementioned skills can be directly applied to future nursing careers and beyond. In addition, this research internship sets a foundation for research interns to integrate, apply and appraise research, exposing them to research as a pathway for ongoing learning and increasing research interns' potential uptake of research in nursing practice. Finally, research opportunities expanded research interns' thinking, thus advancing their critical reasoning and problem-solving skills - important attributes of nursing practice. The importance of early exposure to hands-on research experience is linked to regulatory bodies' expectation of nurses to make informed decisions through best evidence and knowledge translation. As research interns have gained more experience to apprehend evidence through research, they have an increased potential to transform nursing practice. Indeed, nursing research internships have been found to positively influence research interns' professional development, research and scholarly skills and perspective on nursing research. ${ }^{[7,17,20]}$ Furthermore, a 10-week intensive summer research internship found significant benefits to students through mentorship and hands-on research opportunities, and to mentors, who remarked on the energy of students and increased productivity. ${ }^{[16]}$ Considering these points, the outcomes of the QNHR Research Internship are consistent with similar research models.

While there were many successes to the program, there were also identified areas for improvement to enhance the experience for both research interns and faculty members. In particular, there were challenges at times with unclear expectations between faculty members and research interns and faculty member's perceptions of interns' knowledge that did not always align with the actual level of knowledge possessed by interns. Research interns' lack of experience is an important concept for faculty members to recognize and appreciate when engaging with the interns. In the future, unclear expectations may be mediated by enhanced supports such as through the mapping out of timelines and communicating deadlines early on in the research internship. Further scaffolding of the program may be another future program addition, where common learning needs are identified, and more learning opportunities incorporated in bi-weekly meetings to further support research interns' research knowledge. As previously mentioned, regular communication was a key support and asset to the research internship and may have modified communication roadblocks. Research interns identified that having regular meetings with supervisors and biweekly group meetings with faculty, other interns and the research coordinator led to their success. As faculty members in this program were key determinants in student achievement, it is necessary for faculty members to guide interns throughout the research process with supportive measures in order to optimize their learning experience.

\section{Limitations}

Limitations of this study include the interns' (J.K., C.C., S.S.) involvement in both the participation of the survey and the analysis of the results, which may have introduced potential coding bias. However, to enhance trustworthiness, the authors were able to member check the results section with the participants to ensure the quotations reflected the participants' views. Member checking and independent coding reduced potential bias in the analysis process. As a final step, faculty members reviewed the manuscript to assess the validity of results. The small sample size between the faculty members and research interns may decrease the generalizability of the results from this summer nursing research internship program to other university research programs. Lastly, due to the structure of the analysis and the focus of the study, the results primarily captured the short-term effects of the program, which may have limited the full breadth of program outcomes and experiences. In the future, it is recommended to additionally examine long-term outcomes, such as participants' likelihood to pursue further graduate work. Given these limitations, we would also highlight that while the topic of nursing research internships has been well documented, this paper depicts the experiences of research interns and faculty members involved in the inter-collaborative QNHR Research Internship. The QNHR Research Internship is a model that can be replicated and the analysis of partic- 
ipant's experiences builds upon the current evidence that supports early integration of hands-on research experience into undergraduate nursing education.

\section{Conclusion}

Successful research involves effective collaborative teams. This research internship exposed students to basic research skills and knowledge; however, and more importantly, they were able to learn in a collaborative team environment. The unique collaborative model of this program provides an important experiential research experience for nursing students and faculty. Overall, participation in the research internship program is positive; our review and evaluation of research interns' and faculty members' perspectives provides infor- mation for future program development.

\section{ACKNOWLEDgements}

The authors would like to acknowledge the faculty members at Queen's University School of Nursing and the QNHR research interns for providing feedback on their experiences with the research program. The authors would also like to acknowledge the faculty members for their guidance, mentorship and contributions of critical revision to the paper, with special thanks to Dr. Joan Tranmer, Dr. Jacqueline Galica and Ms. Genevieve Pare.

\section{CONFLicts OF INTEREST Disclosure}

The author(s) declare that they have no competing interests.

\section{REFERENCES}

[1] Canadian Nurses Association. Framework for the practice of registered nurses in Canada. 2015.

[2] Kitutu J, Mccall M, Findle R, et al. Beyond one term of mentoring: A new approach to the research mentorship of undergraduate students. Int. J. of Nurs. Sciences. 2016; 3(1): 63-70. https: //doi.org/10.1016/j.ijnss.2016.02.004

[3] Jamerson PA, Fish AF, Frandsen G. Nursing student research assistant program: A strategy to enhance nursing research capacity building in a magnet status pediatric hospital. Appl. Nurs. Res. 2011; 24(2): 110-113. PMid:20974074 https://doi .org/10.1016/j. apnr.2009.08.004

[4] Edwards N, Webber J, Mill J, et al. Building capacity for nurseled research. Int. Nurs. Rev. 2001; 56(1): 88-94. PMid:19239521 https://doi.org/10.1111/j.1466-7657.2008.00683.x

[5] Allari R. Students' experiences in nursing research and evidence based practice course: a qualitative study. Int. J. of Nurs. 2016; 3(10). https://doi.org/10.15640/ijn.v3n2a9

[6] Bloom KC, Olinzock BJ, Radjenovic D, et al. Leveling EBP content for undergraduate nursing students. J. of Prof. Nurs. 2013; 29(4): 217-24. PMid:23910923 https://doi.org/10.1016/j.profnu rs.2012.05.015

[7] Burkhart V, Hall A. Developing the next generation of nurse scientists. Nurse educator. 2015; 40(3): 160-162. PMid:25581434 https://doi.org/10.1097/NNE.0000000000000121

[8] Sackett DL, Straus SE, Richardson WS, et al. Evidence-based medicine: How to practice and teach EBM. 2nd ed. Edinburgh: Churchill Livingstone; 2000. 261 p.

[9] Rousseau DM, Gunia BC. Evidence-based practice: The psychology of EBP implementation. Annual Review of Psychology. 2016; 67(1): 1747. PMid:26361048 https://doi.org/10.1146/annurev-p sych-122414-033336

[10] Aiken LH. Baccalaureate nurses and hospital outcomes: more evidence. Med Care. 2014; 52(10): 861-3. PMid:25215645 https: //doi.org/10.1097/MLR.0000000000000222

[11] Kutney-Lee A, Sloane DM, Aiken LH. An increase in the number of nurses with baccalaureate degrees is linked to lower rates of post- surgery mortality. Health Aff. 2013; 32(3): 579-86. PMid:23459738 https://doi.org/10.1377/hlthaff . 2012.0504

[12] Smith CR, Martsolf DS, Draucker CB, et al. Stimulating research interest and ambitions in undergraduate nursing students: The researchdoctorate pipeline nitiative. The J. of Nurs. Ed. 2016; 55(3): 133-40. PMid:26926213 https ://doi .org/10.3928/01484834-20160 216-03

[13] Vessey JA, DeMarco RF. The undergraduate research fellows program: A unique model to promote engagement in research. J Prof Nurs. 2008; 24(6): 358-63. PMid:19022209 https ://doi.org/10 $.1016 / j$. profnurs .2008 .06 .003

[14] Mitchell K, Rekiere J, Grassley JS. The influence of undergraduate research assistant experiences on future nursing roles. J. of Prof. Nurs. 2019.

[15] Jansen DA, Jadack RA, Ayoola AB, et al. Embedding research in undergraduate learning opportunities. West. J. of Nurs. Research. 2015; 37(10): 1340-58. PMid:25694176 https://doi.org/10.1 $177 / 0193945915571136$

[16] Slattery M, Logan B, Mudge B, et al. An undergraduate research fellowship program to prepare nursing students for future workforce roles. J. of Prof. Nurs. 2016; 32(6): 412-420. PMid:27964811 https://doi.org/10.1016/j.profnurs .2016.03.008

[17] Coyne BM, Kennedy C, Self A, et al. A comprehensive approach to undergraduate nursing students' Research Experiences. J. of Nurs. Ed. 2018; 57(1): 58-62. PMid:29381163 https://doi .org/10.3 928/01484834-20180102-12

[18] Phillips AW. Proper applications for surveys as a study methodology. The West. J. of Emerg. Medicine. 2017; 18(1): 8-11. PMid:28116000 https://doi.org/10.5811/westjem. 2016.11.32000

[19] Nowell LS, Norris JM, White DE, et al. Thematic analysis: striving to meet the trustworthiness criteria. Int. J. of Qualitative Methods. 2017. https://doi.org/10.1177/1609406917733847

[20] Cepanec D, Clarke D, Plohman J, et al. Engaging undergraduate nursing students in research: the students' experience of a summer internship program pilot project. The J. of Nurs. Ed. 2013; 52(8): 466-469. PMid:23855343 https://doi.org/10.3928/014848 34-20130718-03 